\title{
The effectiveness of stem cell therapies on health-related quality of life and life expectancy in comparison with conventional supportive medical treatment in patients suffering from end-stage liver disease
}

\author{
Adeeb M AlZoubi* and Farah Khalifeh \\ See related research article by Salama et al:: http://stemcellres.com/content/3/6/49
}

\begin{abstract}
The work presented in this study focuses on evaluating health-related quality of life using the International Short Form 36-Item Health Survey in chronic liver disease patients in Cairo, Egypt, who received either stem cell therapy (SCT) or supportive medical treatment (SMT). Long-term follow-up results for patients who underwent therapy compared with healthy individuals showed that patients who underwent SCT showed marked improvements on all domains of the evaluation, much lower mortality rates, and complete absence of malignancy, compared with patients enrolled in SMT. The authors clearly showed a significant advantage of SCT in chronic liver disease patients compared with SMT.
\end{abstract}

This cohort study looks at the effectiveness of stem cell therapy (SCT) compared with supportive medical treatment (SMT) on health-related quality of life in patients with chronic liver disease (CLD) [1]. Studies such as this represent a valuable scientific approach, especially in the revolutionary field of stem cell clinical applications [2-4]. Despite the limited available resources and difficulty in carrying out such studies, especially in rural areas, the authors were able to demonstrate a clear and vivid association with better outcomes in patients enrolled in the SCT group compared with the SMT group.

*Correspondence: adeebalzoubi@stemcellsarabia.net Stem Cells of Arabia, PO Box: 2828, 246 Al-Medina Al-Munawwara Street, Amman, Jordan
The authors used the International Short Form 36-Item Health Survey (SF-36 v2) in CLD patients. This survey is considered a wide generic measure of health status with high levels of reliability and validity [5]. There are a few limitations for the SF-36 v2, however, including the lack of consideration for sleep variables among its relative low response or unresponsiveness in some populations [5-7].

One hundred patients with CLD were analyzed against 50 healthy (control) subjects using the SF-36 v2. The time intervals for data collection were appropriate in terms of representing early, intermediate, late, and long-term follow-up periods. Although the authors highlighted a potential weakness in their evaluation where a member of the stem cell therapy team conducted the surveys by himself, we think of this as a positive point. In such studies, we do not recommend relying on patients completing these surveys by themselves. Relying on patients to collect their own data, especially when it comes to chronic diseases, is largely subject to their personal interpretations. The results may be highly affected by many factors, including emotional variations, high variability in educational levels, and dependency on other individuals to answer the questionnaires. As a result, this may increase the rate of personal errors, lack of integrity, and unresponsiveness. We therefore recommend assigning an expert in patient evaluation handling from the same treatment team to carry out this important task.

The authors presented meta-analyzed clusters of results that we consider both unique and interesting. The study elucidates that both SCT and SMT patient groups have shown significantly lower pre-therapy SF-36 v2 scores compared with healthy individuals. Interestingly, the results presented in this report showed a noticeable improvement in all eight of the domains in patients who have received SCT compared with the deterioration 
shown by SMT patients after therapy. Additionally, there was a significant distinction in mortality rates between SCT and SMT groups of $6 \%$ and 38\%, respectively. More interestingly, the lack of malignancy in patients from the SCT group is of profound medical significance [8] for a large population of patients suffering from CLD in a country such as Egypt [9].

However, it is important to highlight a few drawbacks in the study that may be of value to authors in future studies. Some of the data presented in this study are in agreement with published literature, while other data are not. This could most probably be due to variations in patients' profiles and cultural factors, or to differences in executing the study. Regardless of the reason for this disagreement, the authors should have presented a detailed discussion reasoning out their views on agreements and disagreements between their results and previously published reports. Additionally, we think that the literature review section was not fully covered and included a relatively low number of references. Only about one-half of the references cited in the paper were less than 5 years old. This could be either due to the lack of new references in this field or due to the hastiness of authors to deeply investigate the literature. In either case, the authors should have made more effort to fully cover the rationalization in the field of investigation. Moreover, the authors tend to emphasize that their study's outcomes are a reflection of the patients' own perspective that found the overall experience of stem cell therapy a positive one, when other scientifically-based explanations are clearly possible and more reasonable in favoring stem cell therapy.

Collectively, the intensity and magnitude of the work performed in this report clearly manifests prominence in using advanced stem cell therapies for treating CLD. This is especially true in a country such as Egypt, which has the highest prevalence of hepatitis $C$ virus infections in the world [10], with a uniquely high risk profile in these patients to develop hepatocellular carcinoma [11] following CLD. A more focused future study on stem cell therapy in hepatitis $C$ virus-positive patients (that have significantly higher rates of developing hepatocellular carcinoma), and its correlation to reducing their tendency to develop of the malignancy, will be of tremendous importance to this very intriguing field of investigation.

\section{Abbreviations}

CLD, chronic liver disease; SCT, stem cell therapy; SF-36 v2, International Short Form 36-Item Health Survey; SMT, supportive medical treatment.

\section{Competing interests}

The authors declare that they have no competing interests.

Published: 25 February 2013

\section{References}

1. Salama H, Zekri AR, Ahmed R, Medhat I, Abdallah ES, Darwish T, Ahmed OS, Bahnassy A: Assessment of health-related quality of life in patients receiving stem cell therapy for end-stage liver disease: an Egyptian study. Stem Cell Res Ther 2012, 3:49.

2. Takami T, Terai S, Sakaida I: Advanced therapies using autologous bone marrow cells for chronic liver disease. Discov Med 2012, 14:7-12.

3. Takami T, Terai S, Sakaida I: Stem cell therapy in chronic liver disease. Curr Opin Gastroenterol 2012, 28:203-208.

4. Shi M, Zhang Z, Xu R, Lin H, Fu J, Zou Z, Zhang A, Shi J, Chen L, Lv S, He W, Geng H, Jin L, Liu Z, Wang FS: Human mesenchymal stem cell transfusion is safe and improves liver function in acute-on-chronic liver failure patients. Stem Cells Trans/ Med 2012, 1:725-731.

5. Brazier JE, Harper R, Jones NM, O'Cathain A, Thomas KJ, Usherwood T, Westlake L: Validating the SF-36 health survey questionnaire: new outcome measure for primary care. BMJ 1992, 305:160-164.

6. Brazier J: The SF-36 health survey questionnaire - a tool for economists. Health Econ 1993, 2:213-215.

7. Ware JE Jr, Kosinski M, Gandek B, Aaronson NK, Apolone G, Bech P, Brazier J, Bullinger M, Kaasa S, Leplège A, Prieto L, Sullivan M: The factor structure of the SF-36 Health Survey in 10 countries: results from the IQOLA Project. International Quality of Life Assessment. J Clin Epidemio/ 1998, 51:1159-1165.

8. Alison MR, Islam S, Lim S: Stem cells in liver regeneration, fibrosis and cancer: the good, the bad and the ugly. J Pathol 2009, 217:282-298.

9. Mabrouk M, Esmat G, Yosry A, El-Serafy M, Doss W, Zayed N, El-Sahhar M, Awny S, Omar A: Health-related quality of life in Egyptian patients after liver transplantation. Ann Hepatol 2012, 11:882-890.

10. Kandeel AM, Talaat M, Afifi SA, El-Sayed NM, Abdel Fadeel MA, Hajjeh RA, Mahoney FJ: Case control study to identify risk factors for acute hepatitis C virus infection in Egypt. BMC Infect Dis 2012, 12:294.

11. Schiefelbein E, Zekri AR, Newton DW, Soliman GA, Banerjee M, Hung ChW, Seifeldin IA, Lo AC, Soliman AS: Hepatitis C virus and other risk factors in hepatocellular carcinoma. Acta Virol 2012, 56:235-240.

\section{doi:10.1186/scrt164}

Cite this article as: AlZoubi AM, Khalifeh F: The effectiveness of stem cell therapies on health-related quality of life and life expectancy in comparison with conventional supportive medical treatment in patients suffering from end-stage liver disease. Stem Cell Research \& Therapy 2013, 4:16. 